\title{
CARACTERIZAÇÃO E AVALIAÇÃO DAS PROPRIEDADES DE CONCRETOS AUTOADENSÁVEIS COM ADIÇÕES MINERAIS E BAIXO CONSUMO DE CIMENTO
}

\author{
H. A. A. DINIZ1 ${ }^{*}$, J. N. OLIVEIRA ${ }^{2}$, L. P. SILVA ${ }^{3}$, M. S. MACÊDO ${ }^{4}$, M. M. SOUZA ${ }^{5}$ \\ 1, 2,3, 4, 5 Instituto Federal de Educação, Ciência e Tecnologia do Rio Grande do Norte \\ hugo_diniz29@yahoo.com.br*
}

Submetido 02/05/2018 - Aceito 19/10/2018

DOI: $10.15628 /$ holos.2018.7267

\section{RESUMO}

O concreto autoadensável (CAA) possui um elevado teor de materiais finos e vem sendo bastante utilizado devido às suas características de alta fluidez e coesão. Os finos provindos de resíduos ou subprodutos industriais podem vir a ser usados em prol da sustentabilidade, minimizando consideravelmente o consumo de cimento associado à possibilidade de manter, ou melhorar, as propriedades mecânicas ou de durabilidade. Desta forma, o presente artigo tem como objetivo estudar as propriedades do concreto no estado fresco e endurecido, analisando a viabilidade do desenvolvimento de CAA's confeccionados com elevados teores de adições minerais. Para isso, o cimento foi substituído por adições minerais (resíduo de biomassa de cana-de-açúcar ou
\end{abstract}

pozolana da casca do arroz e metacaulim) no teor de $50 \%$, com base no traço de referência, que tem um consumo de $442,6 \mathrm{~kg} / \mathrm{m}^{3}$ de cimento, originando novos traços com consumos de cimento entre $215,9 \mathrm{~kg} / \mathrm{m}^{3}$ e $216,2 \mathrm{~kg} / \mathrm{m}^{3}$. Os CAA's foram caracterizados no estado fresco pelos ensaios de Slump-Flow Test, T500, Anel-J, Funil-V e caixa-L, aferindo-se a influência da inserção das adições nas propriedades reológicas e no consumo de aditivo superplastificante. Para avaliação do desempenho mecânico dos CAA's, foram realizados ensaios de resistência à compressão. Os CAA's com adições minerais apresentaram desempenho mecânico satisfatório.

\section{CHARACTERIZATION AND EVALUATION OF THE PROPERTIES OF SELF- COMPACTING CONCRETES WITH MINERAL ADDITIONS AND LOW CONSUMPTION OF CEMENT}

\begin{abstract}
The self-compacting concrete (SCC) has a high content of fine materials and has been widely used due to its characteristics of high fluidity and cohesion. Fines from industrial waste or by-products may be used for the sake of sustainability, considerably reducing the consumption of cement associated with the possibility of maintaining or improving mechanical or durability properties. In this way, this article aims to study the properties of concrete in the fresh state and hardened state, analyzing the feasibility of the development of SCC made with high levels of mineral additions. For this, the cement was replaced by mineral additions (sugar cane biomass residue or pozzolan from rice husk and metakaolin) in
\end{abstract}

the $50 \%$ content, based on the reference trait, which consumes $442.6 \mathrm{~kg} / \mathrm{m}^{3}$ of cement, giving new traits with cement consumption between $215.9 \mathrm{~kg} / \mathrm{m}^{3}$ and 216.2 $\mathrm{kg} / \mathrm{m}^{3}$. The SCC were characterized in the fresh state by the Slump-Flow Test, T500, J-ring, V-funnel and L-box assays, assessing the influence of the insertion of the additions on the rheological properties and the superplasticizer additive consumption. In order to evaluate the mechanical performance of the SCC, compressive strength tests were performed. The SCC with mineral additions presented satisfactory mechanical performance.

KEYWORDS: Self-compacting concrete, fresh state, mineral additions, mechanical performance. 


\section{INTRODUÇÃO}

A indústria do cimento consome boa parte dos recursos minerais e naturais do nosso planeta, além de ser uma das maiores emissoras de $\mathrm{CO}_{2}$ (dióxido de carbono) do mundo, contribuindo com cerca de $7 \%$ das emissões globais (Mehta \& Monteiro, 2014), devido a processos que envolvem a formação do clínquer. Nesse contexto, o concreto - produto industrializado mais utilizado pela sociedade - tem sua mistura composta por cerca de $12 \%$ de cimento, $8 \%$ de água e $80 \%$ de agregados miúdos e graúdos (Mehta \& Monteiro, 2014). Dessa forma, a indústria do concreto possui um alto potencial de causar impactos ambientais.

Atualmente, o processo de fabricação do concreto está passando por uma remodelação, utilizando-se cada vez mais resíduos industriais e adições minerais, tais como a pozolana da casca do arroz (PCA), o resíduo da biomassa da cana-de-açúcar (RBC) e o metacaulim (MK). Hodiernamente, estudos estão sendo desenvolvidos no âmbito do concreto autoadensável (CAA), o qual cada vez ganha mais espaço no mercado devido à sua alta fluidez (causada pelo uso de superplastificantes), que dispensa qualquer tipo de vibração de adensamento e diminui consideravelmente o tempo de execução das peças de concreto.

No campo das adições, as cascas de arroz, também conhecidas como palhas de arroz, são carapaças produzidas durante a operação de beneficiamento do arroz colhido (Fonseca, 2016). Podem ser usadas como insumo que possa vir a substituir parcialmente o cimento na produção do concreto, e, dessa forma, ter suas propriedades utilizadas em benefício da indústria deste, visando a diminuição de custos e a preservação das reservas naturais. O resíduo da biomassa da cana-deaçúcar, é, também, utilizado para os mesmos fins, mostrando-se como uma solução de logística mais viável ao mercado norte rio-grandense em relação à pozolana da casca do arroz.

Os CAA's têm um maior consumo de finos, objetivando atender os requisitos de desempenho nos estados fresco e endurecido e atuando como pontos de nucleação, aumentando a velocidade da reação das partículas do cimento com a água e melhorando a zona de transição (Tutikian \& Dal Molin, 2008). Portanto, as adições minerais pozolânicas ou inertes e os materiais cimentícios suplementares surgem como uma solução para que se diminua o consumo do cimento no concreto e que se mantenha a quantidade de finos.

Estudou-se no presente artigo o comportamento das adições minerais de PCA, RBC e MK na confecção do CAA, dando-se uma maior atenção para o RBC, visto que é um potencial produto regional de custo expressivamente inferior ao custo do PCA e características físico-químicas semelhantes, podendo vir a ser um mecanismo de economia para o RN. Esta análise consistiu em comparar o desempenho de misturas com mesmo teor de RBC e PCA no intuito de avaliar o comportamento do RBC em relação ao PCA, produto este já comercializado, e, sequencialmente, mapeando tal comportamento em teores de RBC diferentes.

\section{FUNDAMENTAÇÃO TEÓRICA}

O concreto é apontado como o material mais utilizado por toda a indústria da construção civil. Sua importância se dá, principalmente, no que diz respeito à sustentação e estabilidade de 
toda a construção, seja ela de pequeno, médio ou grande porte. Define-se concreto como sendo uma mistura homogênea de cimento, agregados miúdos e graúdos com ou sem a incorporação de aditivos ou adições (ABNT NBR 12655, 2015a). Um de seus componentes principais, o cimento Portland, têm se mostrado, nos últimos anos, como um agente nocivo à natureza, tanto em seu processo fabril quanto no processo de extração de sua matéria-prima. Nesse âmbito, surgem as adições minerais, que visam substituir parte do cimento usado na mistura sem comprometer a quantidade de finos resultante.

Nessa esfera, o concreto autoadensável (CAA) surge como uma das maiores inovações no ramo da construção civil. Segundo Safiuddin, West e Soudki (2012), o CAA é um concreto altamente fluido que se espalha sozinho, preenche todos os espaços das fôrmas e alcança a condição perfeita de adensamento somente através do seu próprio peso quando em seu estado fresco; é um concreto que possui uma quantidade de finos elevada e conta com a adição de superplastificantes, os quais the conferem suas propriedades reológicas de auto adensamento, preenchimento e fluidez.

No intuito de diminuir o impacto da indústria do concreto no meio ambiente, estão sendo testadas e analisadas adições minerais que possam vir a ser incorporadas ao CAA sem alterar a sua quantidade de finos e sem comprometer significativamente suas propriedades reológicas. Dentre elas, nós destacamos o resíduo da biomassa da cana-de-açúcar (RBC), a pozolana da casca do arroz (PCA) e o metacaulim (MK).

Uma dessas adições advém da casca do arroz, que é um subproduto da operação de beneficiamento do arroz colhido, que, quando incinerada na faixa de $500^{\circ} \mathrm{C}$ a $800^{\circ} \mathrm{C}$, produz um material amorfo: a pozolana da casca do arroz - PCA (Saffiudin et al., 2012). A cada tonelada de arroz, $200 \mathrm{~kg}$ de casca são gerados, que, quando incinerados, chegam a gerar cerca de $40 \mathrm{~kg}$ de cinzas (Mehta \& Monteiro, 2014). Geralmente, tal resíduo é descartado aos montes em campos abertos, gerando uma considerável poluição ambiental (Le \& Ludwig, 2016)

Após ser incinerada, a casca do arroz incorpora características pozolânicas notáveis. O PCA, ao ser adicionado à mistura de concreto fresco, aumenta consideravelmente a viscosidade do produto final, visto que, a nível molecular, sua superfície de contato é surpreendentemente alta, potencializando a retenção de água. Isso se mostra benéfico no tocante à não segregação da mistura, porém se mostra prejudicial à manutenção das habilidades passantes e de preenchimento do CAA, devido ao aumento de viscosidade. Isso pode ser satisfatoriamente solucionado ao adicionar-se um aditivo superplastificante eficiente à mistura. (Saffiudin et al., 2012)

A pozolana da casca de arroz reage com o cimento e reduz a porosidade da matriz cimentícia, assim como reduz a largura da zona de transição interfacial. Porém, segundo Saffiudin et al. (2012), a trabalhabilidade do CAA é reduzida, assim como suas propriedades reológicas. Foise observado que o diâmetro do Slump-Flow Test diminui se constantes forem mantidos o teor de aditivos superplastificantes e a relação água/finos, além da constatação que os tempos no ensaio do Funil-V aumentam e a habilidade passante do CAA diminui, visto que a razão de bloqueio no ensaio da Caixa-L aumenta (Kannan \& Ganesan, 2014). Segundo Le e Ludwig (2016), tal comportamento ocasionado pela incorporação da cinza da casca do arroz ao CAA demonstra a capacidade que esta tem de tornar a mistura mais viscosa, ocasionando o aumento no tempo do 
ensaio do Funil-V e o aumento do desnível no Anel-J. O principal fator que acarreta esse tipo de comportamento é a elevada superfície de contato do PCA, que demanda um consumo de água mais elevado em relação ao consumo de água requerido pelo cimento.

As adições também podem diminuir o custo do CAA, visto substituem parcialmente o cimento, diminuindo o consumo desse fino. As adições de aditivos minerais também melhoram as propriedades estruturais do CAA, além de reduzir a emissão de $\mathrm{CO}_{2}$ (Damtoft, Lukasik, Herfort, Sorrentino \& Gartner al., 2008). O metacaulim (MK), por sua vez, é um material amigável ao meio ambiente, sem produção de $\mathrm{CO}_{2}$, comumente utilizado em misturas de concreto autoadensável.

O MK é um material amorfo obtido pela desidratação de caulino a uma temperatura de cerca de $800^{\circ} \mathrm{C}$ (Fortes-Revilla, Martínez-Ramires \& Blanco-Varela, 2006). A alta reatividade do MK com o cimento e sua usabilidade para acelerar a hidratação do cimento o diferenciam de outros materiais pozolânicos (Vejmelková, Keppert, Grzeszczyk, Skaliński \& Černý 2011; Justice \& Kurtis, 2007), É verificado que o metacaulim acelera o tempo de ajuste inicial e melhora as propriedades mecânicas e de transporte, especialmente porque também pode atingir alta resistência à compressão em uma idade precoce (Shekarchi, Bonakdar, Bakhshi, Mirdamadi \& Mobasher, 2010).

As propriedades reológicas da mistura do concreto autoadensável com o metacaulim são caracterizadas por um estresse de rendimento significativo e uma viscosidade relativamente baixa. A resistência do concreto autoadensável com o metacaulim cresce muito rápido durante o período de endurecimento inicial e permanece significativamente em outras idades. A partir de pesquisas anteriores (Fonseca, 2016; Saffiudin et al., 2012), verificou-se que o concreto que contém PCA e MK funciona melhor em relação à durabilidade e alguns outros atributos relacionados.

O principal foco do nosso estudo, o resíduo da biomassa da cana-de-açúcar (RBC), vem ganhando destaque no âmbito científico da engenharia civil no que diz respeito à sua ação no concreto. De acordo com dados do levantamento feito pela Conab em abril de 2017, a produção de cana-de-açúcar estimada para a safra 2017/18 é de 647,6 milhões de toneladas. Segundo dados do relatório da Federação das Indústrias do Estado de São Paulo(FIESP) e Centro das Indústrias do Estado de São Paulo(CIESP) (2001), cada tonelada de cana produzida resulta em aproximadamente $6,2 \mathrm{~kg}$ de cinza residual.

Como uma adição mineral, o RBC pode desempenhar um papel importante para a resistência e durabilidade do concreto, tanto física quanto quimicamente (Tutikian \& Dal molin, 2008). Os primeiros estudos sobre o aproveitamento desse resíduo foram realizados por Hernández, Middendorf, Gehrke \& Budelmann (1998), que analisou que a cinza do bagaço da cana-de-açúcar produzida nas caldeiras da indústria do açúcar e do álcool pode ser classificada como um provável material pozolânico. Ele apresenta um alto teor de sílica na sua composição, o que o torna uma fonte suplementar de aditivo mineral e pozolana para a produção de materiais cimentícios (Anjos \& Martinelli, 2008).

Sua atividade é influenciada pelas altas temperaturas e de combustão incompleta que ocorrem nas caldeiras, que, em alguns casos, podem ser desprezíveis. Algumas condições influenciam negativamente a reatividade, como é o caso do grau de cristalinidade da sílica presente nas cinzas e a presença de impurezas, tais como o carbono e o material não queimado, 
que podem limitar o contato entre sílica e o hidróxido de cálcio reativo para formar compostos estáveis (Hernandéz et al., 1998).

O efeito físico possui três etapas principais: o efeito fíller, que é o preenchimento dos vazios da mistura pelas minúsculas partículas das adições, causando um aumento da densidade; o refinamento da estrutura de poros e dos produtos de hidratação do cimento, causado pelas pequenas partículas das adições que podem agir como pontos de nucleação para os produtos da hidratação; e a alteração da microestrutura da zona de transição, reduzindo ou eliminando o acúmulo de água livre que, normalmente, fica retido sobre os agregados (Tutikian \& Dal molin, 2008). Nesse contexto, a cinza da biomassa da cana de açúcar pode manter a resistência à compressão e proporcionar refinamento dos poros através do efeito fíller (Cordeiro, Filho, Tavares e Fairbairn, 2012).

Destarte, é através da capacidade de reação do hidróxido de cálcio $\left(\mathrm{Ca}(\mathrm{OH})_{2}\right)$ que ocorre o efeito químico das adições minerais supracitadas, onde é derivado um composto resistente - o CS--H (silicato de cálcio hidratado) -, que ocupa os vazios de maiores dimensões existentes na pasta de cimento ou na zona de transição, aumentando o desempenho mecânico e a durabilidade do concreto (Tutikian \& Dal Molin, 2008).

\section{METODOLOGIA}

Esta pesquisa teve como objetivo central verificar o comportamento de concretos autoadensáveis no estado fresco e endurecido sob a influência das adições minerais do resíduo da biomassa da cana-de-açúcar e da pozolana da casca do arroz, com a adição de metacaulim, além de um aditivo superplastificante para atingir a autoadensabilidade. Para tanto, partiu-se de um traço referência de concreto autoadensável e dois outros traços, com substituição de $50 \%$ do cimento pelas adições minerais, em relação à mistura de referência.

\subsection{Materiais empregados}

1. Cimento Portland Mizu CP V ARI;

2. Agregado Miúdo (areia branca fina);

3. Agregado Graúdo (brita com diâmetro máximo de $12,5 \mathrm{~mm}$ );

4. Aditivo químico superplastificante glenium SCC 160, fabricação BASF;

5. Resíduo da biomassa da cana-de-açúcar (RBC), cedido pela usina Estivas, localizada em Arez, RN;

6. Pozolana da casca do arroz (PCA);

7. Metacaulim (MK).

Os materiais foram caracterizados conforme a NBR NM 23 (ABNT, 2001a), que disserta sobre a massa específica de finos; as NBR NM 52 (ABNT, 2009a) e NM 53 (ABNT, 2009b), que dissertam sobre a massa específica de agregados, e conforme a NBR NM 248 (ABNT, 2001b), que discorre sobre a granulometria dos agregados graúdos e miúdos. Os resultados foram apresentados nos Gráficos 1 e 2 e na Tabela 1. 


\section{AREIA}



Gráfico 1 - Granulometria do agregado miúdo (areia)

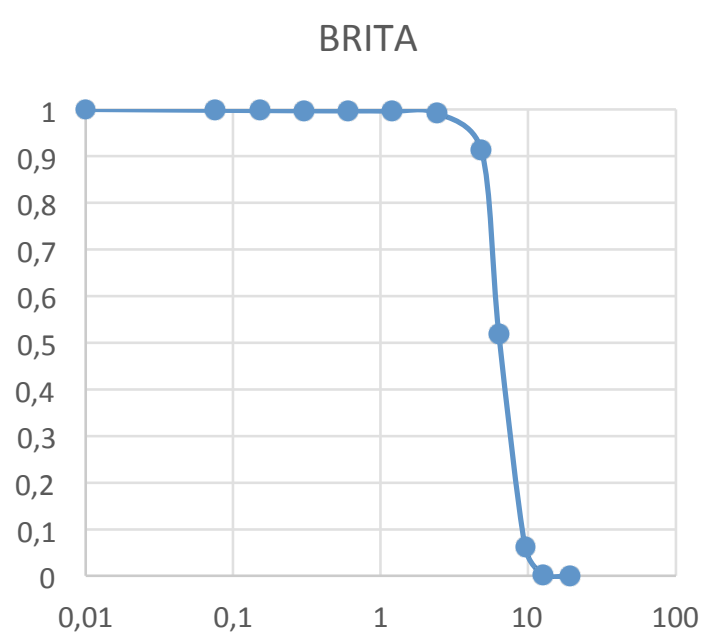

Gráfico 2 - Granulometria do agregado graúdo (brita)

Tabela 1 - Caracterização dos materiais

\begin{tabular}{c|c|c|c|c|c|c}
\hline CARACTERÍSTICA & AREIA & BRITA & PCA & RBC & MK & CIMENTO \\
\hline Massa específica $\left(\mathrm{kg} / \mathrm{dm}^{3}\right)$ & 2,64 & 2,67 & 2,15 & 2,10 & 2,55 & 3,05 \\
\hline Diâmetro máximo $(\mathrm{mm})$ & 2,4 & 12,5 & - & - & - & - \\
\hline Módulo de finura & 2,20 & 8,475 & - & - & - & - \\
\hline
\end{tabular}

\subsection{Mistura}

Inicialmente, estipulou-se o traço referência e o percentual de $50 \%$ de substituição do cimento pelas adições minerais. Mediante estudo bibliográfico prévio, previu-se que o comportamento do RBC e PCA na viscosidade da mistura inviabilizaria o traço neste teor de substituição, o que se fez definir um teor de $20 \%$ de metacaulim, mantendo o objetivo da análise comparativa entre o RBC e PCA com $30 \%$ de substituição ao cimento. A Tabela 2 apresenta os consumos dos materiais utilizados em cada mistura.

Tabela 2 - Traços utilizados

\begin{tabular}{c|c|c|c}
\hline \multicolumn{5}{c}{ TRAÇOS UTILIZADOS } \\
\hline Consumo & C100 & R30MK20 & P30MK20 \\
\hline Cimento $\left(\mathrm{kg} / \mathrm{m}^{3}\right)$ & 442,639 & 215,943 & 216,253 \\
\hline $\mathrm{RBC}\left(\mathrm{kg} / \mathrm{m}^{3}\right)$ & 0,000 & 129,566 & 0,000 \\
\hline $\mathrm{PCA}\left(\mathrm{kg} / \mathrm{m}^{3}\right)$ & 0,000 & 0,000 & 129,752 \\
\hline $\mathrm{MK}\left(\mathrm{kg} / \mathrm{m}^{3}\right)$ & 0,000 & 86,377 & 86,501 \\
\hline Areia $\left(\mathrm{kg} / \mathrm{m}^{3}\right)$ & 841,014 & 708,294 & 709,311 \\
\hline Brita $\left(\mathrm{kg} / \mathrm{m}^{3}\right)$ & 841,014 & 932,875 & 943,215 \\
\hline $\begin{array}{c}\text { Aditivo Glenium SCC } \\
160(\% \text { sobre a massa } \\
\text { do cimento) }\end{array}$ & 0,61 & 2,5 & 2,2 \\
\hline Água $\left(\mathrm{kg} / \mathrm{m}^{3}\right)$ & 221,320 & 215,943 & 216,253 \\
\hline
\end{tabular}


Em seguida, a mistura foi efetuada em uma betoneira com capacidade de 150 litros, obedecendo-se à seguinte sequência com tempos determinados de execução, de acordo com a Tabela 3. Sequencialmente, imagens do procedimento de mistura, conforme Figura 3.

Tabela 3 - Sequência da mistura na betoneira

\begin{tabular}{l|l|c}
\hline \multicolumn{1}{c|}{ Passos } & \multicolumn{1}{|c|}{ Material misturado } & Tempo de mistura \\
\hline $1^{\circ}$ passo & Agregado graúdo $+30 \%$ da água & 30 segundos \\
\hline $2^{\circ}$ passo & $50 \%$ da areia $+20 \%$ da água & 30 segundos \\
\hline $3^{\circ}$ passo & Cimento + Metacaulim + 50\% da areia $+40 \%$ da água & 2 minutos \\
\hline $4^{\circ}$ passo & Aditivo superplastificante Glenium SCC 160 & 2 minutos \\
\hline $5^{\circ}$ passo & PCA ou RBC $+10 \%$ da água & 3 minutos \\
\hline
\end{tabular}

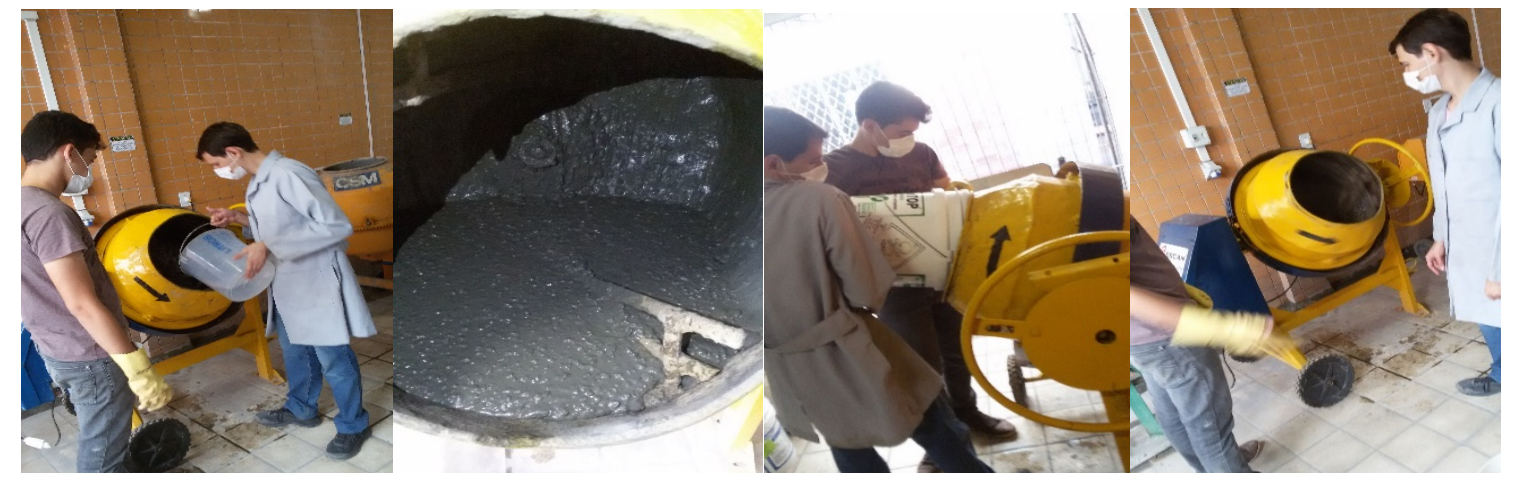

Figura 3 - Procedimento prático da mistura

Após a confecção da mistura, moldaram-se corpos de prova cilíndricos com as dimensões $10 \times 20 \mathrm{~cm}$, obedecendo-se às dimensões prescritas na norma NBR 5738 (ABNT, 2015a) para os ensaios de resistência à compressão. Vale salientar que a moldagem dos corpos de prova não necessitou de golpes para adensamento, visto que o concreto é autoadensável.

\subsection{Ensaios de caracterização do CAA no estado fresco}

O ensaio de Slump-Flow Test foi realizado de acordo com a NBR 15823-2 (ABNT, 2017a), onde é medido o diâmetro final do concreto espalhado para determinar a fluidez do concreto autoadensável, em fluxo livre, sobre a ação do seu próprio peso. Já o ensaio de T500, que consiste numa derivação do Slump-Flow Test, é realizado simultaneamente a este último, observando-se o tempo em que mistura leva para atingir o diâmetro de $500 \mathrm{~mm}$, avaliando-se a viscosidade do concreto, conforme prescreve a NBR 15823-1 (ABNT, 2017b). A Tabela 4 mostra os parâmetros para os respectivos ensaios de Slump-Flow Test e T500 segundo as normas supracitadas.

Tabela 4 - Parâmetros normativos para os ensaios de Slump-Flow Test e T500

\begin{tabular}{c|c|c|c|c|c}
\hline \multicolumn{3}{|c|}{ Slump-Flow Test } & \multicolumn{3}{c}{ T500 } \\
\hline Classe & $\begin{array}{c}\text { Espalhamento } \\
(\mathrm{mm})\end{array}$ & $\begin{array}{c}\text { Método de } \\
\text { ensaio }\end{array}$ & Classe & $\begin{array}{c}\text { T500 } \\
(\mathrm{s})\end{array}$ & $\begin{array}{c}\text { Método de } \\
\text { ensaio }\end{array}$ \\
\hline SF1 & 550 a 650 & NBR & VS1 & $\leq 2$ & NBR \\
\cline { 1 - 2 } SF2 & 660 a 750 & VS2 & $>2$ & $15823-2$ \\
\hline SF3 & 760 a 850 & $15823-2$ & & & 1582 \\
\hline
\end{tabular}


Com a finalidade de medir a fluidez das misturas e suas respectivas habilidades passantes diante de obstáculos como armaduras densas, foi-se realizado, segundo a NBR 15823-3 (ABNT, 2017c), o ensaio do Anel J. O resultado é obtido pela diferença entre o diâmetro médio de espalhamento obtido no ensaio Slump-Flow Test e o obtido no ensaio do Anel J, classificando o concreto como autoadensável de acordo com a classe de viscosidade plástica aparente. A Tabela 5 mostra os parâmetros para o ensaio do Anel J segundo a sua respectiva NBR.

Tabela 5 - Parâmetros normativos para o ensaio do Anel J

\begin{tabular}{c|c|c}
\hline \multicolumn{3}{c}{ Anel J } \\
\hline Classe & $\begin{array}{c}\text { Espalhamento } \\
(\mathrm{mm})\end{array}$ & $\begin{array}{c}\text { Método de } \\
\text { ensaio }\end{array}$ \\
\hline PJ1 & $\begin{array}{c}\text { 0 a 25, com 16 } \\
\text { barras de aço }\end{array}$ & \multirow{2}{*}{ NBR 15823-3 } \\
\hline PJ2 & $\begin{array}{c}25 \text { a 50, com 16 } \\
\text { barras de aço }\end{array}$ \\
\hline
\end{tabular}

No intuito de analisar a viscosidade do concreto, conjuntamente ao T500, foi-se realizado o ensaio do Funil-V, segundo as prescrições da NBR 15823-5 (ABNT, 2017d), o qual se consiste numa simulação de uma situação em que o concreto precisa escoar em ambientes confinados. A viscosidade aparente do concreto é determinada aferindo-se o tempo em que a pasta demora para escoar totalmente pelo Funil-V. A Tabela 6 mostra os parâmetros para o ensaio do funil-V, segundo a sua respectiva NBR.

Tabela 6 - Parâmetros normativos para o ensaio do Funil-V

\begin{tabular}{c|c|c}
\hline \multicolumn{3}{c}{ Funil-V } \\
\hline Classe & Tempo de escoamento (s) & Método de ensaio \\
\hline VF1 & $<9$ & NBR 15823-5 \\
\hline VF2 & 9 a 25 & \\
\hline
\end{tabular}

\subsection{Ensaios de caracterização do CAA no estado endurecido}

Foram realizados ensaios de resistência à compressão axial, executados de acordo com a NBR 5739 (ABNT, 2009c), para as idades de 3, 7 e 28 dias, sendo rompidos, para cada idade, três corpos de prova com as dimensões de $10 \times 20 \mathrm{~cm}$, em conformidade com a NBR 5738 (ABNT, 2015b). Anteriormente aos ensaios, os corpos de prova foram retificados para regularização da face inferior, caso fosse necessário, e da face superior. Para realização do ensaio, utilizou-se a prensa hidráulica do Laboratório de Materiais e Produtos Cimentícios do IFRN Campus NatalCentral, da marca Pavitest, com capacidade de 100 ton e precisão de 10 kgf.

\section{RESULTADOS E DISCUSSÕES}

Os traços foram inicialmente determinados para atingir o maior diâmetro possível sem exsudação no Slump-Flow Test, no intuito de verificar e comparar a viscosidade dos traços com adições minerais em relação ao traço referência e a influência dessas em conjunto com o aditivo superplastificante no comportamento do CAA. Na Tabela 7 são apresentados os resultados dos ensaios realizados no CAA em seu estado fresco. 
Tabela 7 - resultado dos ensaios

\begin{tabular}{l|c|c|c}
\hline \multicolumn{1}{c|}{ Ensaio } & C100 & R30MK20 & P30MK20 \\
\hline Slump-Flow Test Test (diâmetro em mm) & 776 & 748 & 780 \\
\hline T500 (em segundos) & 1,2 & 3,1 & 2,9 \\
\hline Anel-J (diâmetro em mm) & 730 & 718 & 770 \\
\hline Anel-J (h1-h2 em cm) & 1,0 & 0,9 & 0,6 \\
\hline V-Test: tempo (em segundos) & 3,05 & 11,3 & 11,1 \\
\hline Teor de aditivo (\%) & 0,61 & 2,5 & 2,2 \\
\hline
\end{tabular}

\subsection{Resultados da habilidade de preenchimento (fluidez)}

Analisando-se os resultados apresentados no Gráfico 3, verifica-se que o traço C100 e o traço P30MK20 tiveram sua classe de consistência classificada com SF 3, enquanto que o traço R30MK20 apresentou classe de consistência SF 2, conforme os parâmetros da NBR 15823-1 (ABNT, 2017b). Com isso, pode-se afirmar que o RBC tem um maior poder viscosificador, o que possibilita uma maior coesão da pasta e um menor risco de segregação da mistura. Mesmo com o teor máximo de aditivo superplastificante $(2,5 \%)$, o RBC apresentou um diâmetro menor no ensaio Slump-flow Test. Portanto, o RBC e o PCA necessitaram de maiores teores de aditivo para atingir ou se aproximar do diâmetro equivalente ao do traço referência.

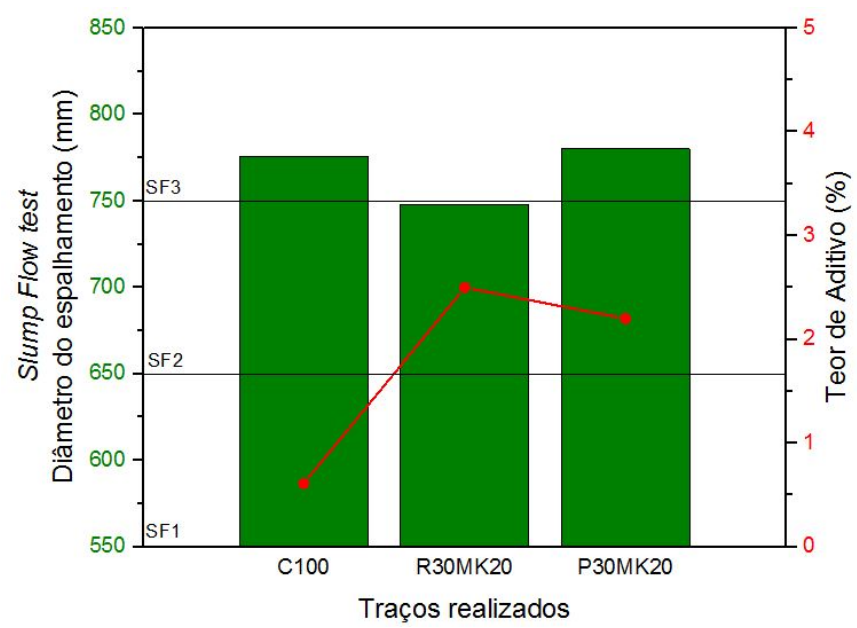

Gráfico 3 - Relação entre teor de aditivo e diâmetro de abertura no ensaio de Slump-Flow Test

\subsection{Resultados da habilidade passante}

Os resultados do ensaio do Anel J mostram que as misturas contendo RBC e PCA apresentam uma melhor habilidade passante, visto que possuem uma maior viscosidade (Gráfico 4). Isso se expressa na coesão da mistura e no maior contato sólido-sólido proporcionados pelas adições minerais (Medeiros, 2016). É também exposto no Gráfico 4 um tratamento matemático desses resultados, visto que é possível relacionar a tangente da função obtida entre o diâmetro de abertura do ensaio de Slump-Flow Test (DS) com o diâmetro de abertura do ensaio do Anel J (DA). 


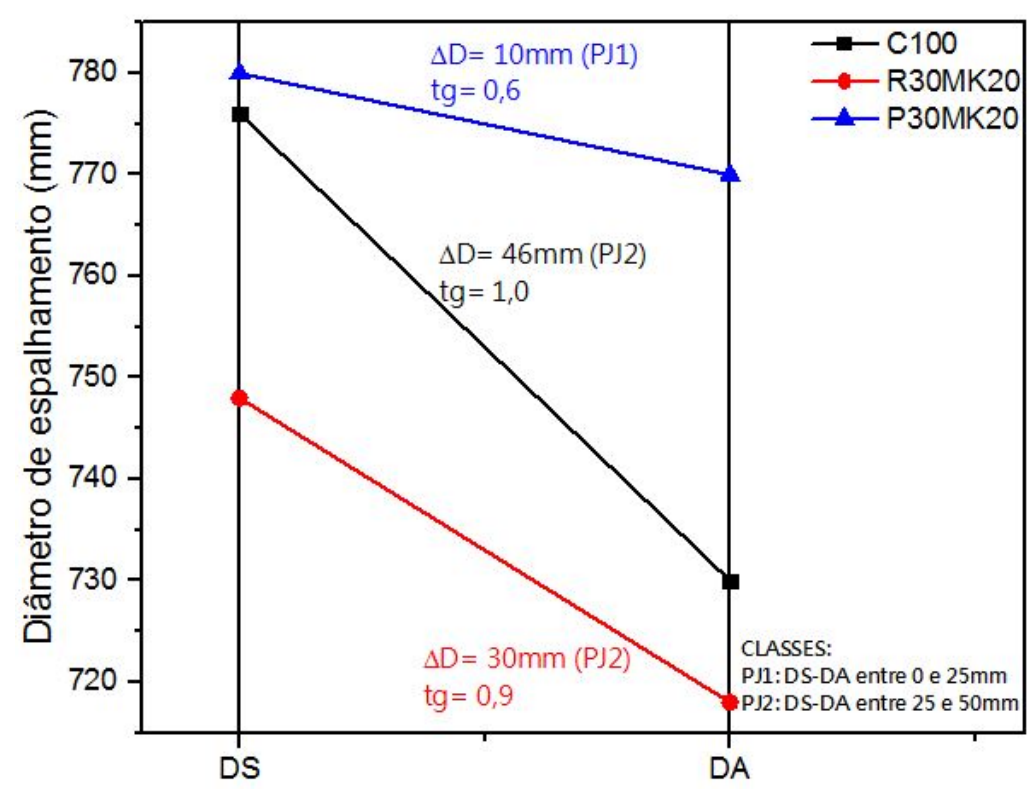

Gráfico 4 - Relação entre os diâmetros do Slump-Flow Test (DS) e Anel J (DA)

Aferindo-se a tangente da semirreta obtida pela relação entre os diâmetros, o traço referência C100 apresentou a maior inclinação dentre todos os traços apresentados, o que ratifica sua menor habilidade passante e consequentemente uma maior propensão à segregação dos agregados da pasta. Os traços com adições minerais tiveram comportamento antagônico ao traço referência, devido à presença das adições minerais. O traço P30MK20 obteve a menor tangente, apresentando as melhores características no que se refere à habilidade passante do concreto, resultado esse provavelmente devido à área superficial do PCA ser menor do que a do RBC. Estudos realizados com o mesmo material do presente artigo comprovam esta conclusão pelo método BET (Medeiros, 2016; Anjos et al., 2009), estando ainda em conformidade com estudos relacionados a outras fontes (Kannan \& Ganesan, 2014).

Além disso, infere-se, também, que a diferença entre as alturas h1 e $\mathrm{h} 2(\Delta \mathrm{h})$ no ensaio do Anel J corroboram para as conclusões anteriormente obtidas, visto que quanto menor a 1,0 for essa diferença, maior coesão e habilidade passante a mistura terá. Ainda neste gráfico, pode-se perceber que tais valores de $\triangle \mathrm{h}$ implicam que o PCA possui uma maior finura e uma geometria espacial menos lamelar em relação ao RBC, o que pôde ser comprovado pelos ensaios realizados por Anjos et al. (2012) e Saffiudin et al. (2012). Verificando-se a diferença entre os diâmetros de espalhamento obtidos nos ensaios do Anel J e do Slump-Flow Test, podemos classificar, segundo a NBR 15823-3 (ABNT, 2017c), que os traços C100 e R30MK20 pertencem à classe de viscosidade aparente PJ2, enquanto que o traço P30MK20 pertence à classe PJ1, o que corrobora com a discussão anteriormente realizada acerca dos resultados dos ensaios.

\subsection{Análise da viscosidade}

Analisando-se os tempos de execução dos ensaios T500, Anel J e Funil V, no Gráfico 5, observa-se que o traço referência apresentou tempos aproximados nos três ensaios realizados e inferiores às misturas com adições. Isto é devido ao poder viscosificante das adições reduzir a velocidade de escoamento e espalhamento da mistura, conferindo a elas um comportamento semelhante entre si. Pôde-se verificar, também, que ambos os ensaios apresentaram 
comportamentos linearmente semelhantes, o que induz a uma homogeneidade do concreto no decorrer dos ensaios, atribuindo a este a propriedade de estabilidade. Esse comportamento também ratifica os resultados do ensaio, uma vez que a ordem de grandeza é diferente. Segundo a NBR 15823-2 (ABNT, 2017b) e 15823-5 (ABNT, 2017d), os traços com adições minerais caracterizaram-se como classe de viscosidade plástica VS 2 no ensaio T500 e classe VF 2 de viscosidade plástica aparente no Funil V, enquanto que o traço C100 possui classes VS1 e VF1 nos respectivos ensaios anteriormente citados.

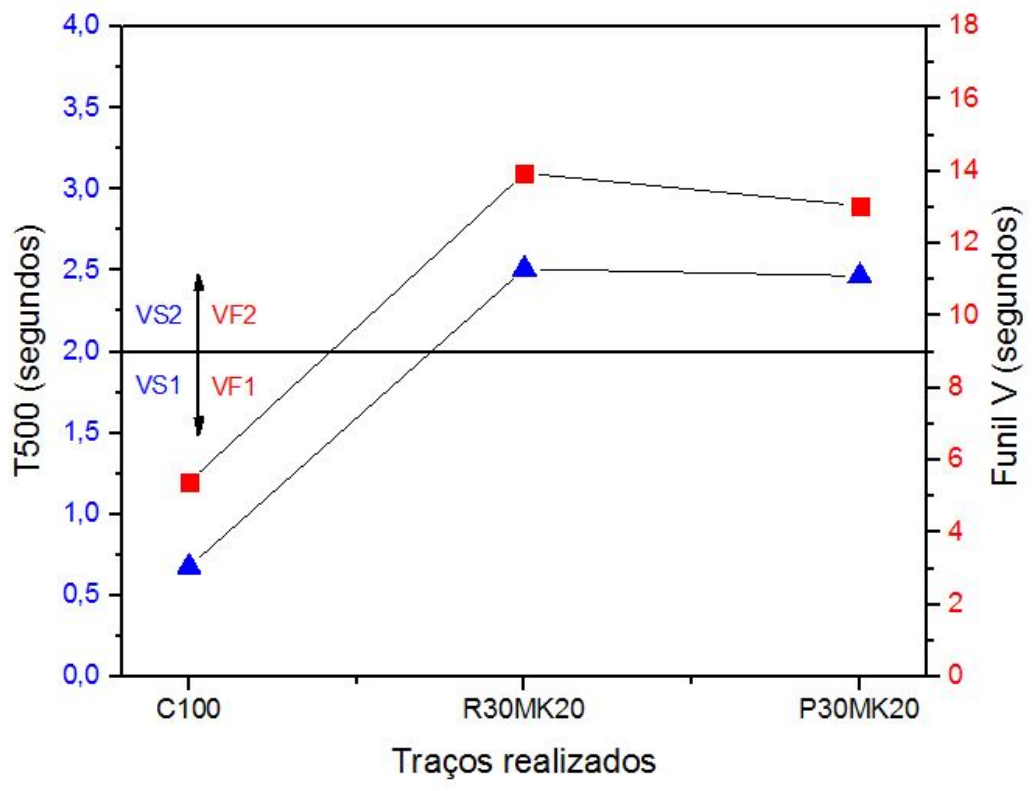

Gráfico 5 - Relação entre os tempos de execução dos ensaios de Caixa-L, Funil V e T500

\subsection{Resistência à compressão}

A resistência à compressão - Gráfico 6 - nas primeiras idades apresentou melhores resultados para o traço referência, em função da quantidade de cimento empregada no traço ser maior do que nas outras misturas e, consequentemente, pela maior quantidade de produtos hidratados formados. Contudo, quanto ao PCA e ao RBC, a resistência aumenta a partir de 7 dias, indicando que as adições possuem uma boa atividade pozolânica, formando os produtos hidratados em tempo posterior ao tempo do traço C100. É interessante notar, na Tabela 8, que o PCA tem uma reatividade mais rápida que o RBC, tendo seu pico de crescimento entre os 3 e os 7 dias. Já o RBC tem sua reatividade vista de maneira mais significativa entre no intervalo de 7 a 28 dias, apresentando pico de aumento de atividade pozolânica semelhante ao do PCA. Esta diferença no tempo de reatividade das entre adições é devido à finura, e, consequentemente, à maior área superficial do PCA, como visto nos estudos supracitados.

Tabela 8 - Aumento percentual da atividade pozolânica do RBC e do PCA em relação às primeiras idades

\begin{tabular}{c|c|c}
\hline Traço & $\mathbf{3 - 7}$ dias & $\mathbf{7 - 2 8}$ dias \\
\hline C100 & $22 \%$ & $15 \%$ \\
\hline P30MK20 & $129 \%$ & $39 \%$ \\
\hline R30MK20 & $94 \%$ & $110 \%$ \\
\hline
\end{tabular}




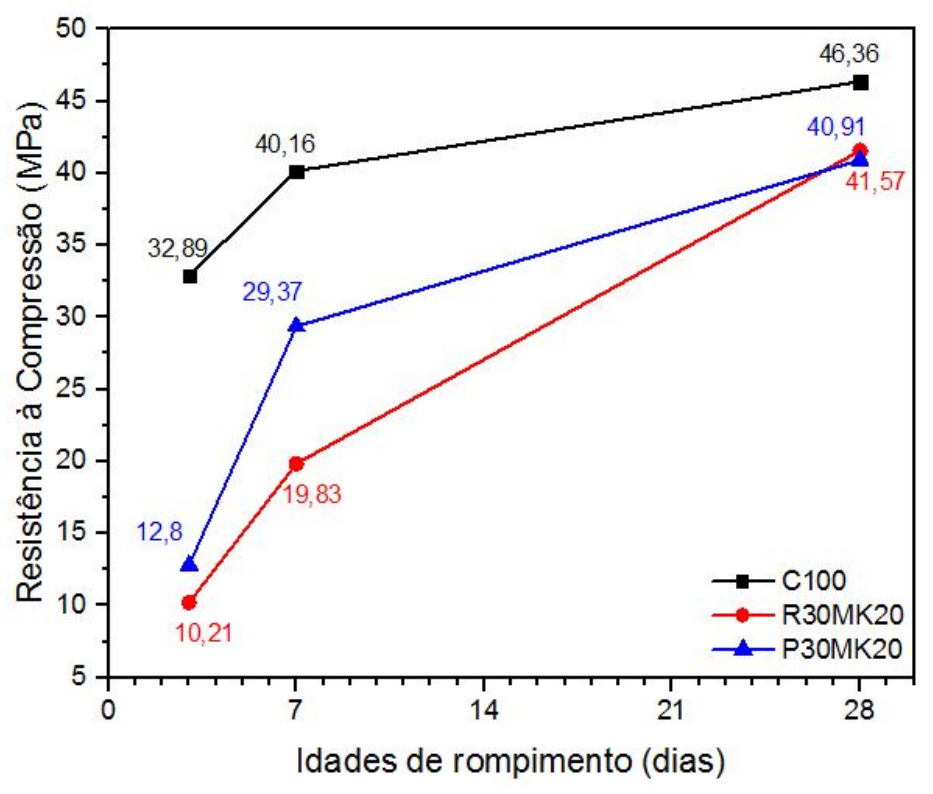

Gráfico 6 - Resistência aos 28 dias

\section{CONSIDERAÇÕES FINAIS}

Os traços realizados com $50 \%$ de substituição do cimento pelas adições minerais de RBC e PCA possuíram bons resultados de resistência à compressão aos 28 dias e conferiram um aumento da viscosidade do CAA em relação ao traço referência, permitindo uma maior coesão da mistura sem alterar significativamente o tempo de espalhamento do Anel J e do T500, alterando na faixa de 8,15 s o tempo de escoamento no Funil V.

A habilidade passante do CAA foi melhorada nos traços com adições minerais devido à coesão promovida pelas adições, possibilitada por suas altas áreas superficiais e pela geometria da estrutura dos grãos. Devido a essa melhoria na habilidade passante, verificou-se que o CAA apresentou uma maior viscosidade da mistura, visto que a presença das adições colaborou com um maior contato sólido-sólido entre os componentes da matriz cimentícia. Isso contribui para a diminuição do risco de segregação da pasta, permitindo um CAA com um melhor adensamento.

Os objetivos iniciais traçados no presente artigo foram atingidos, quer seja no tocante ao objetivo se obter um CAA eficiente e sustentável com adições minerais, quer seja no âmbito de mostrar que adições como o RBC têm um potencial comercial significativo na indústria do concreto. Os CAA's obtidos com a substituição de $50 \%$ do cimento por adições obedeceram aos limites normativos quanto às características reológicas e resistência à compressão.

\section{REFERÊNCIAS}

Anjos, M. A. S., Ferreira, D. F., \& Borja, E. V. (2012). INFLUÊNCIA DA FINURA DO RESÍDUO DE BIOMASSA DA CANA-DE-AÇÚCAR NA ATIVIDADE POZOLÂNICA COM A CAL. Holos, 2, 44-57.

Anjos, M. A. S., \& Martinelli, A. E. (2008). Caracterização do resíduo da Biomassa da cana-deaçúcar para aplicação em pastas cimentícias. In CEBECiMat-Congresso Brasileiro de Engenharia e Ciências do Matérias-Porto de Galinhas-PE. 
ANJOS, M. Adição do resíduo de biomassa da cana-de-açúcar em pastas para cimentação de poços petroliferos produtores de óleos pesados. 2009. $172 f$ (Doctoral dissertation, Tese (Doutorado em Ciências e Engenharia de Materiais)-Programa de Pós-Graduação em Ciências e Engenharia de Materiais, Universidade Federal do Rio Grande do Norte. Natal).

ASSOCIAÇÃO BRASILEIRA DE NORMAS TÉCNICAS (ABNT) (2001a). NBR NM 23: Cimento Portland e outros materiais em pó - Determinação de massa específica. Rio de Janeiro.

ASSOCIAÇÃO BRASILEIRA DE NORMAS TÉCNICAS (ABNT) (2001b). NBR NM 248: Agregados Determinação da composição granulométrica. Rio de Janeiro.

ASSOCIAÇÃO BRASILEIRA DE NORMAS TÉCNICAS (ABNT) (2007). NBR 5739: Concreto - Ensaios de compressão de corpos-de-prova cilíndricos. Rio de Janeiro.

ASSOCIAÇÃO BRASILEIRA DE NORMAS TÉCNICAS (ABNT) (2009a). NBR NM 52: Agregado miúdo Determinação de massa específica e massa específica aparente. Rio de Janeiro.

ASSOCIAÇÃO BRASILEIRA DE NORMAS TÉCNICAS (ABNT) (2009b). NBR NM 53: Agregado graúdo Determinação de massa específica, massa específica aparente e absorção de água. Rio de Janeiro.

ASSOCIAÇÃO BRASILEIRA DE NORMAS TÉCNICAS (ABNT) (2015a). NBR 12655:2015: Concreto de cimento Portland - Preparo, controle, recebimento e aceitação - Procedimento. Rio de Janeiro.

ASSOCIAÇÃO BRASILEIRA DE NORMAS TÉCNICAS (ABNT) (2015b). NBR 5738: Concreto Procedimento para moldagem e cura de corpos de prova. Rio de Janeiro: Abnt, 2015. 9 p.

ASSOCIAÇÃO BRASILEIRA DE NORMAS TÉCNICAS (ABNT) (2017a). NBR 15823-1: Concreto autoadensável - Parte 1: Classificação, controle e recebimento no estado fresco. Rio de Janeiro.

ASSOCIAÇÃO BRASILEIRA DE NORMAS TÉCNICAS (ABNT) (2017b). NBR 15823-2: Concreto autoadensável - Parte 2: Determinação do espalhamento, do tempo de escoamento e do índice de estabilidade visual - Método do cone de Abrams. Rio de Janeiro.

ASSOCIAÇÃO BRASILEIRA DE NORMAS TÉCNICAS (ABNT) (2017c). NBR 15823-3: Concreto autoadensável - Parte 3: Determinação da habilidade passante - Método do anel J. Rio de Janeiro.

ASSOCIAÇÃO BRASILEIRA DE NORMAS TÉCNICAS (ABNT) (2017d). NBR 15823-5: Concreto autoadensável - Parte 5: Determinação da viscosidade - Método do funil V. Rio de Janeiro.

Companhia Nacional de Abastecimento (CONAB) (2014). Acompanhamento safra brasileira canade-açúcar, v. 1 - Safra 2014/15, n.4 - Quarto Levantamento, Brasília, pp. 1-29, abr. 2015.

Cordeiro, G. C., Toledo Filho, R. D., Tavares, L. M., \& Fairbairn, E. M. R. (2012). Experimental characterization of binary and ternary blended-cement concretes containing ultrafine residual rice husk and sugar cane bagasse ashes. Construction and Building Materials, 29, 641-646.

Damtoft, J. S., Lukasik, J., Herfort, D., Sorrentino, D., \& Gartner, E. M. (2008). Sustainable development and climate change initiatives. Cement and concrete research, 38(2), 115-127. 
FIESP/CIESP. Ampliação da Oferta de Energia Através da Biomassa. São Paulo, 2001. MINISTÉRIO DA AGRICULTURA. Ministério da Agricultura, Pecuária e Abastecimento. 2007. http://www.agricultura.gov.br (acesso em 30 de Maio de 2008)

Fonseca, T. V. (2016). Avaliação de concretos autoadensáveis com baixos consumos de cimento incorporando metacaulim, pozolana da casca do arroz, fíler calcário e adição de cal hidratada (Master's thesis, Brasil).

Fortes-Revilla, C., Martínez-Ramírez, S., \& Blanco-Varela, M. T. (2006). Modelling of slaked limemetakaolin mortar engineering characteristics in terms of process variables. Cement and Concrete Composites, 28(5), 458-467.

Hernández, J. M., Middendorf, B., Gehrke, M., \& Budelmann, H. (1998). Use of wastes of the sugar industry as pozzolana in lime-pozzolana binders: study of the reaction. Cement and Concrete Research, 28(11), 1525-1536.

Justice, J. M., \& Kurtis, K. E. (2007). Influence of metakaolin surface area on properties of cementbased materials. Journal of materials in civil engineering, 19(9), 762-771.

Kannan, V., \& Ganesan, K. (2014). Chloride and chemical resistance of self compacting concrete containing rice husk ash and metakaolin. Construction and Building Materials, 51, 225-234.

Le, H. T., \& Ludwig, H. M. (2016). Effect of rice husk ash and other mineral admixtures on properties of self-compacting high performance concrete. Materials \& Design, 89, 156-166.

Medeiros, F. K. D. (2016). Estudo de concretos autoadensáveis com reduzidos teores de cimento e elevados teores de adições minerais (Master's thesis, Brasil).

MEHTA, P. K., \& Monteiro, P. J. (2008). Concreto-Microestrutura, Propriedades e Materiais. 3a edição. São Paulo: Pini. 673p.

Safiuddin, M., West, J. S., \& Soudki, K. A. (2012). Properties of freshly mixed self-consolidating concretes incorporating rice husk ash as a supplementary cementing material. Construction and Building Materials, 30, 833-842.

Shekarchi, M., Bonakdar, A., Bakhshi, M., Mirdamadi, A., \& Mobasher, B. (2010). Transport properties in metakaolin blended concrete. Construction and Building Materials, 24(11), 22172223.

Tutikian, B. F., \& Dal Molin, D. C. (2008). Concreto auto-adensável. São Paulo: PINI.

Vejmelková, E., Keppert, M., Grzeszczyk, S., Skaliński, B., \& Černý, R. (2011). Properties of selfcompacting concrete mixtures containing metakaolin and blast furnace slag. Construction and Building Materials, 25(3), 1325-1331. 